\title{
Taxonomic levels, in marine community studies, revisited
}

\author{
P. J. Somerfield*, K. R. Clarke \\ Plymouth Marine Laboratory, Prospect Place, The Hoe, Plymouth PL1 3DH, United Kingdom
}

\begin{abstract}
The utility of analyses of abundance data at taxonomic levels higher than species, in the interpretation of results from marine surveys, is examined using nematode and macrofauna data from a sublittoral dredgings disposal site and from an intertidal site known to be influenced by heavy metal pollution. A more objective approach than has hitherto been the case in comparisons of multivariate patterns from data at different taxonomic levels is taken, and the concept of a 'second-stage' multidimensional scaling (MDS), in which rank correlations between pairs of similarity matrices themselves become the elements of a second similarity matrix, an ordination of which gives a summary of the conclusions, is introduced. It is shown that analyses of both the sublittoral and intertidal estuarine nematode communities are robust to aggregation to the level of genus, but further aggregation alters the perceived pattern of impact. Aggregation of macrofauna abundances to families has only a small effect on analyses of the sublittoral community, and none on analyses of the less diverse intertidal macrofauna. Aggregating macrofauna data to phyla has some effect on consequent analyses in both situations. Whichever component of the benthos is examined, and at whatever taxonomic level the analyses are carried out, interpretable results are possible, especially if the pattern of community change is marked, as in both surveys examined in this study.
\end{abstract}

KEY WORDS: Nematodes Macrofauna - Taxonomic levels Community structure - Rank correlations

\section{INTRODUCTION}

In 1986 the community ecology group at an IOC/ GEEP workshop analysed macrofauna and meiofauna data from a putative pollution gradient in Frierfjord and Langesundfjord, Norway (Bayne et al. 1988). One of their findings was that the usual methods of data analysis appear to be very robust to the aggregation of the species data into higher taxonomic groupings (Heip et al. 1988, Herman \& Heip 1988, Warwick 1988 a, b). These observations were, however, made on a single data set. Warwick (1988c) analysed a further 5 data sets, describing the species composition of benthic assemblages ( 3 macrofauna and 2 meiofauna) in relation to gradients of pollution, using univariate and multivariate analyses on species data aggregated to a range of hierarchical taxonomic levels. The general conclusion from these and other (Ferraro \& Cole 1990, Gray et al. 1990, Warwick et al. 1990) studies has

·E-mail:pjso@pml.ac.uk been that for sublittoral soft sediment benthic macrofaunal communities surprisingly little information is lost, even if specimens are identified to the level of phylum, whereas for meiofauna information is lost above the level of families.

Studies in which multivariate analyses of species abundance data aggregated to higher taxonomic levels have been compared have largely relied on simple, subjective, comparisons such as the visual examination of 2-dimensional ordinations or dendrograms for common structure. The 3 macrofaunal data sets examined by Warwick (1988c) consisted of unreplicated temporal or spatial series. Whereas visualisation techniques such as ordination allow the investigator to make inferences about changes in community structure where replication is inadequate, many benthic surveys are not simply descriptive, but are designed in such a way as to address certain a priori hypotheses. Warwick et al. (1990) were able to show, in an adequately replicated survey in Hamilton Harbour, Bermuda, that the significance of differences in macrofauna community structure was 
altered in analyses at the level of phylum. The relative merits of different components of the benthos in marine pollution studies are discussed by Warwick (1993).

The extent to which aggregation to higher taxonomic levels affects resulting analyses depends on the distribution of species amongst higher taxa in the original samples. Whereas taxonomic aggregation may have a limited effect on analyses of data from diverse sublittoral communities, it is not clear whether this is also true in situations where the communities are less diverse. In particular, in estuarine intertidal communities, it is possible that aggregation may have less of an effect on consequent analyses. More generally, aggregation to higher taxa may not affect analyses of meiofaunal and macrofaunal community data to the same extent, or in the same way.

The present study utilises non-parametric multivariate techniques to examine the effects of taxonomic aggregation in 2 ways. The first is to examine how the pattern of perceived impact changes as species are aggregated, and the second is to examine the effect that this has on consequent analyses.

\section{DATA}

Two sets of species abundance data were used. Both consisted of replicated nematode and macrofauna species abundance data from sites where a clear response to anthropogenic disturbance had been demonstrated.
Liverpool Bay, UK. Nematode abundance data from 4 replicate Craib cores (a deliberate corer) and macrofauna abundance data from 4 replicate Day grabs were taken at 7 stations (numbered 1 to 7 ) along a transect through a dredgings disposal site in September 1991. In this shallow sublittoral community, 98 species of nematodes and 97 species of macrofauna were present, and a clear response to dredgings disposal at Stns 4 and 5 is shown in analyses of both meiofauna and macrofauna (Somerfield et al. 1995).

Fal estuary system, UK. Nematode abundance data from 5 cores and macrofauna abundance data from 5 cores were taken from intertidal mudflats in each of 5 creeks (Restronguet, Mylor, Pill, St Just and Percuil) in November 1991. A total of 79 species of nematodes and 23 species of macrofauna were present in the data set and differences in community structure, in both the meiofauna and macrofauna, are related to differences in sediment metal concentrations between creeks (Somerfield et al. 1994a, b).

\section{METHODS}

Nematode abundances were aggregated to the levels of genus, family and, at a higher level, into 4 trophic groups (sensu Wieser 1953) Macrofauna abundances were aggregated to the levels of genus, family and phylum. The majority of the analytical techniques used are described in Clarke \& Warwick (1994b) and are included in PRIMER, a suite of computer programs

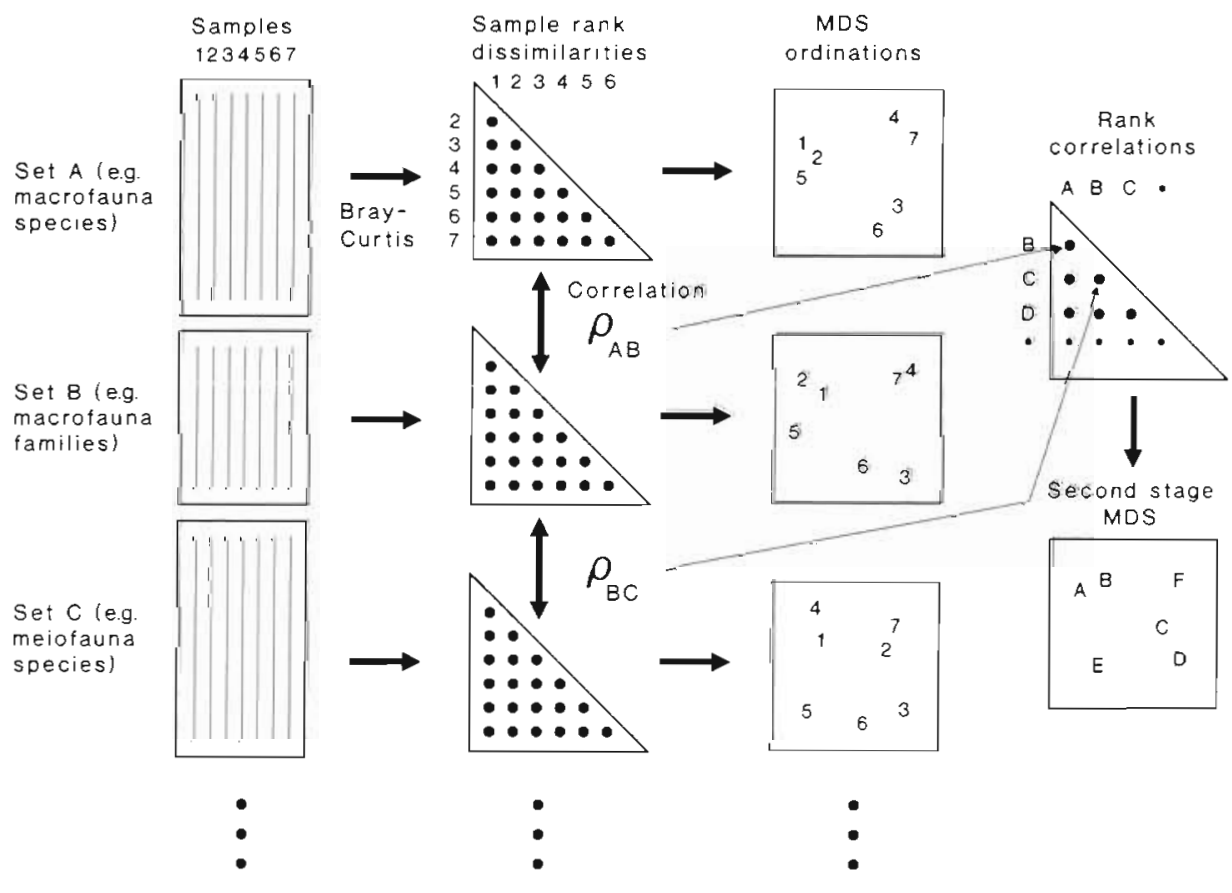

Fig. 1 Schematic diagram of the stages in quantifying and displaying agreement in multuvarate pattern 
developed at the Plymouth Marine Laboratory. Transformations are used to reduce contributions to similarity by abundant taxa, and therefore to increase the importance of the less abundant taxa in the analyses (Clarke 1993), and as nematodes and macrofauna vary in abundance between single individuals and thousands of specimens within samples, a fourth root transformation was applied throughout. Ranked matrices of similarities among samples were constructed using the Bray-Curtis similarity measure (Bray \& Curtis 1957). These matrices were compared by means of a procedure used by Clarke \& Warwick (1994a) to examine community patterns for evidence of common biotic structure, and by Clarke et al. (1993), in a study of disturbance in coral communities, to measure the degree to which community change conforms to a linear sequence. A Spearman rank correlation $(\rho)$ was computed between the corresponding elements of each pair of matrices (Fig. 1), and the significance of the correlation determined by a permutation procedure, using the PRIMER program RELATE (Clarke \& Warwick $1994 \mathrm{~b}$ ). Note that a permutation procedure is essential here because the standard tables for testing $\rho$ are invalidated by the lack of independence of elements of a similarity matrix.

Ordination was by non-metric multidimensional scaling (MDS) (Kruskal \& Wish 1978, Clarke \& Green 1988), and formal significance tests for differences between groups were performed using the ANOSIM permutation test (Clarke \& Green 1988, Clarke 1993), again necessary because 'classical' statistical approaches to significance testing are not valid for typical community matrices.

\section{RESULTS}

MDS ordinations of nematode and macrofauna abundance data from Liverpool Bay (Fig. 2) and the Fal estuary (Fig. 3) indicate that as abundances are aggregated to higher taxonomic levels the overall patterns of community structure are retained. Note that the plots from the highest taxonomic levels have the lowest stress values, which reflect the extent to which the MDS preserves inter-sample relationships in a 2-dimensional plot (Kruskal's stress formula 1). Results of tests for differences between the similarity matrices underlying these ordinations (Table 1) show, not unexpectedly, that the matrices are highly correlated at all taxonomic levels, and the correlations between matrices derived from nematode and macrofauna data are also highly significant. Thus, at both sites, nematode and macrofauna data aggregated to a range of taxonomic levels present a similar pattern. For matrices derived from nematode abundance data, correla-
Nematodes
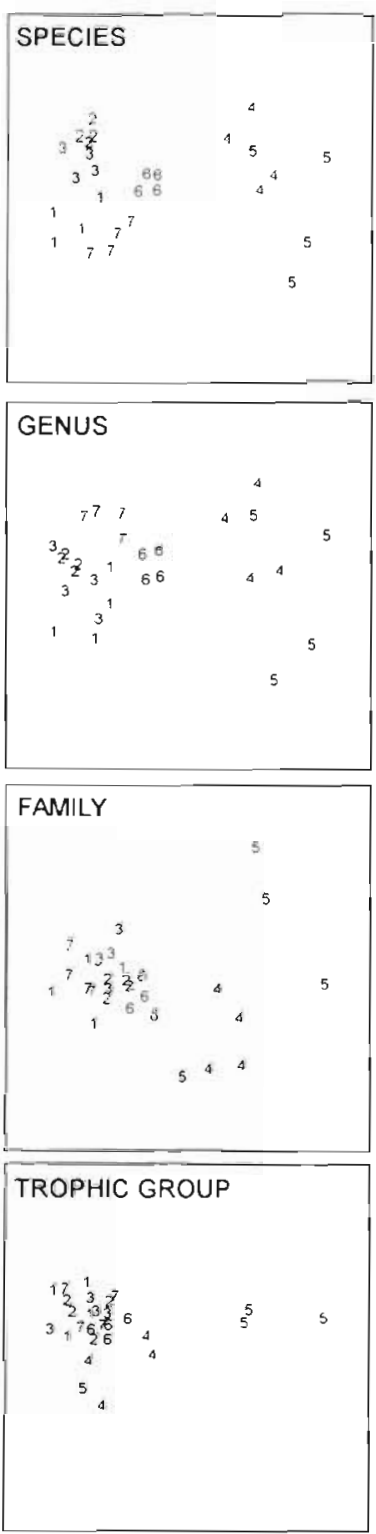

Macrofauna
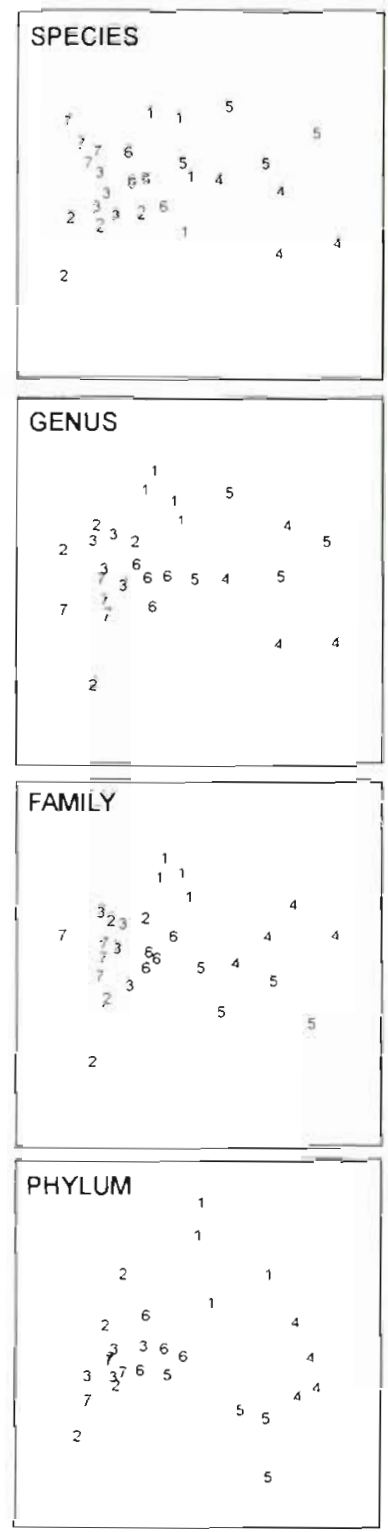

Fig. 2. MDS ordinations from transformed abundances of, left column, nematode species (stress $=0.14$ ), genera $(0.14)$, families $(0.13)$, trophic groups $(0.07)$ and, right column, macrofauna species (stress $=0.16$ ), genera $(0.15)$, families $(0.16)$ and phyla (0.12) from Liverpool Bay. Numbers refer to Stns 1 to 7

tions decrease as taxonomic levels increase, for example nematode genera are more highly correlated with nematode species than they are to nematode families. This is also the case for matrices derived from macrofauna abundance data at the levels of species, genera and families, but the relationships between matrices derived from abundances of macrofauna phyla and lower taxonomic levels are not as clear.

If it is true that aggregation of abundance data from less diverse communities has less of an effect, then cor- 
relations between matrices derived from macrofauna, and also to a lesser extent nematode, data from the Fal estuary should be higher than those from Liverpool Bay. This is generally true (Table 1) with the exception of correlations with matrices derived from abundances of nematode trophic groups

To visualise these interrelationships we can use the inter-matrix correlations (Table 1) as input similarities in the creation of 'second-stage' MDS ordinations (Fig. 1), so that the distance between taxonomic groups in the ordinations reflects the degree to which the similarity matrices are correlated. The ordination from the sublittoral communities of Liverpool Bay (Fig. 4) shows that, for nematodes, matrices derived from abundances of species and genera are very similar, and differences between them and matrices derived from abundances of macrofauna species, genera and families are fairly consistent. As nematode abundances are aggregated to families and trophic groups, and macrofauna to phyla, relative differences increase, in opposite directions. In the estuarine situation (Fig. 4) the pattern is similar with some subtle but interesting contrasts. As might be expected, the matrices derived from abundances of macrofauna species, genera and families form a tight cluster. Nematode species and genus level matrices are also very similar, and there is a pattern of increasing relative difference between matrices derived from nematode abundances aggregated to higher taxonomic levels, as in the ordination from the sublittoral data. The difference is that in the

Table 1. Pairwise Spearman rank correlations between similarity matrices, derived from nematode and macrofauna species abundance data, aggregated to a range of taxonomic levels. $N$ : nematodes; $M$ : macrofauna; $S$ : species; $G$ : genera; F: families; T: trophic groups; P: phyla. All correlations are significantly different from zero, by a permutation test (RELATE), at least at $\mathrm{p}<0.001$

\begin{tabular}{|ccccccccc|}
\multicolumn{7}{c}{ Liverpool Bay } \\
NG & 0.975 & & & & & & \\
NF & 0.826 & 0.847 & & & & & \\
NT & 0.706 & 0.736 & 0.823 & & & & \\
MS & 0.570 & 0.563 & 0.497 & 0.381 & & & \\
MG & 0.575 & 0.571 & 0.512 & 0.400 & 0.984 & & \\
MF & 0.588 & 0.578 & 0.513 & 0.397 & 0.970 & 0.979 & \\
MP & 0.502 & 0.493 & 0.444 & 0.329 & 0.750 & 0.741 & 0.759 \\
& $N S$ & NG & NF & NT & MS & MG & MF \\
Fal estuary & & & & & & \\
NG & 0.977 & & & & & & \\
NF & 0.888 & 0.902 & & & & & \\
NT & 0.685 & 0.693 & 0.780 & & & & \\
MS & 0.616 & 0.585 & 0.589 & 0.559 & & & \\
MG & 0.615 & 0.582 & 0.587 & 0.552 & 0.999 & & \\
MF & 0.609 & 0.573 & 0.590 & 0.549 & 0.982 & 0.984 & \\
MP & 0.493 & 0.479 & 0.477 & 0.506 & 0.799 & 0.793 & 0.769 \\
& $N S$ & $N G$ & NF & NT & MS & MG & MF \\
& & & & & & & \\
\hline
\end{tabular}

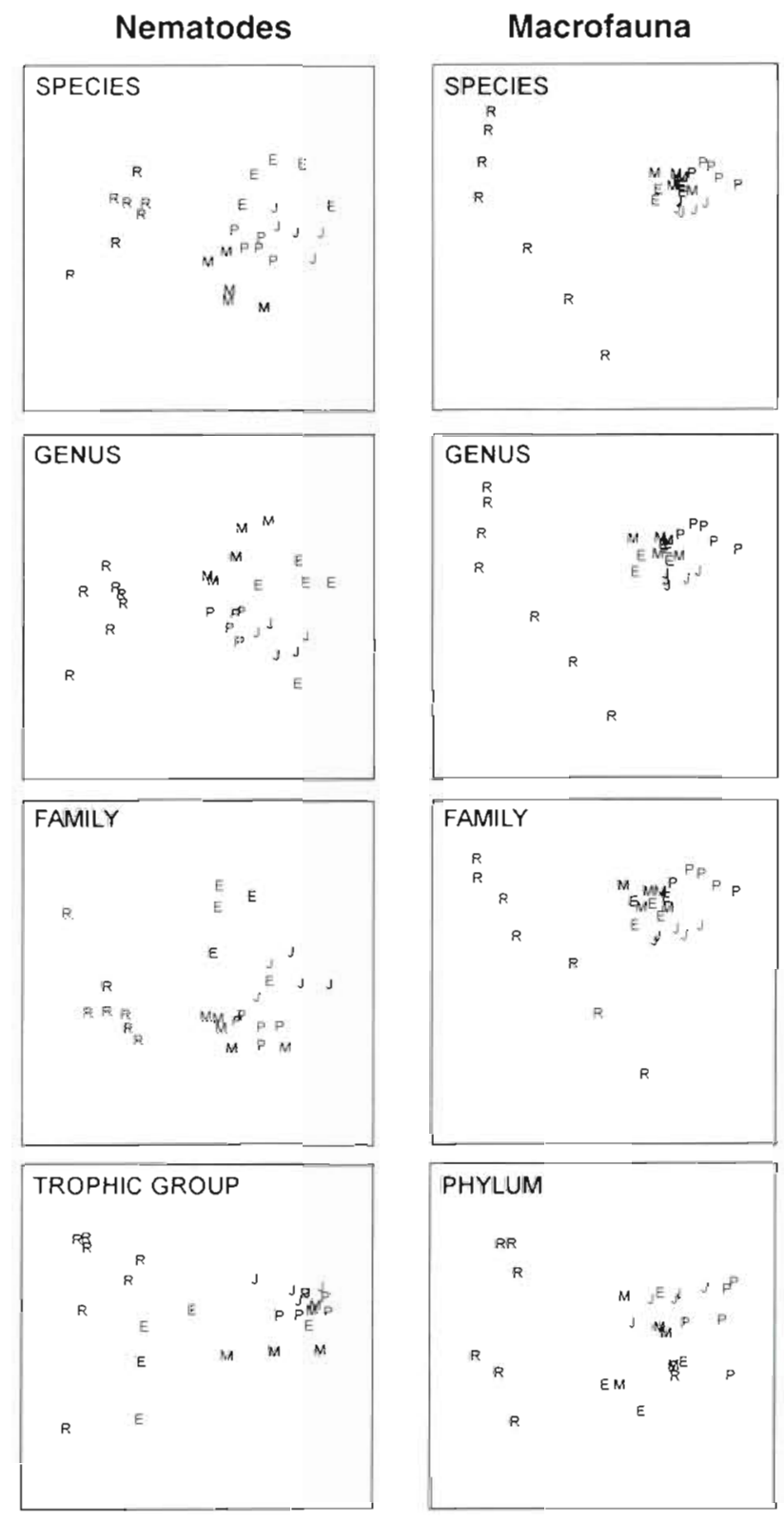

Fig. 3. MDS ordinations from transformed abundances of, left column, nematode species (stress $=0.12)$, genera $(0.13)$, families $(0.10)$, trophic groups $(0.06)$ and, right column, macrofauna species (stress $=0.07$ ), qenera (0.08), families $(0.09)$ and phyla (0.01) from creeks (R: Restronguet; $\mathrm{M}$ : Mylor; P: Pill; $\mathrm{J}$ : St Just; E: Percuily in the Fal estuary system

Fal estuary the pattern is not as divergent, and the correlations between matrices derived from macrofauna species, genera and families, compared with matrices derived from nematode abundances at all taxonomic levels, are consistent.

To examine the effect of using aggregated data on subsequent analyses 1 -way ANOSIM was used to test for significant differences in community structure be- 


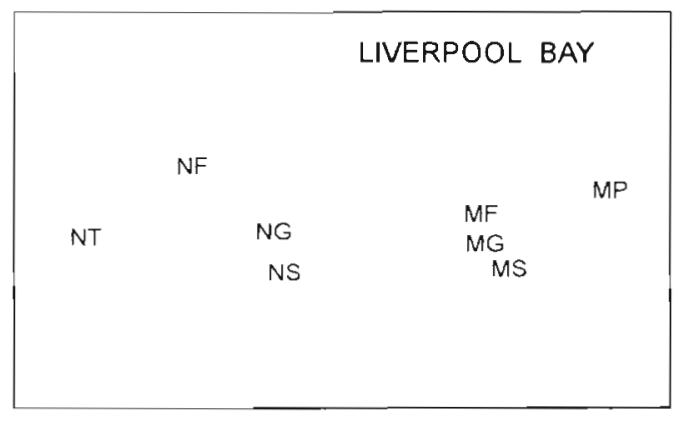

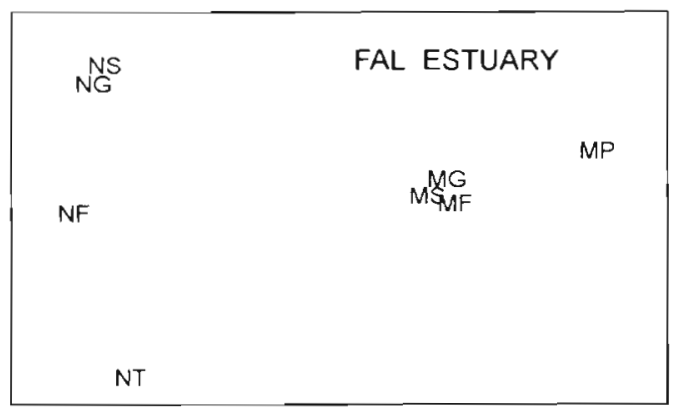

Fig. 4. 'Second-stage' ordinations, by MDS, of ranked intermatrix rank correlations (Table 1$)_{i}$ stress $=0.01$ tween the 7 stations in Liverpool Bay, and between the 5 creeks in the Fal estuary system, using all 8 similarity files from each site (Table 2). Values of the ANOSIM statistic $(R)$ in the global tests for differences between groups decrease strongly in analyses of nematode data from Liverpool Bay, and consistently if less strongly in analyses of nematode data, aggregated to the level of genus and above, from the Fal estuary. Thus, as nematode data are aggregated, the ability of ANOSIM to discriminate between stations decreases. For macrofauna this does not appear to be the case. $R$ values do decrease in analyses of aggregated data from the Fal estuary, but the value for phyla at Liverpool Bay is actually higher than the value for genera or families, though the range of actual values is small, and differences are too slight to be interpretable.

In the majority of analyses, however, it is the pattern of significant pairwise differences that is used to infer an effect. Owing to the strong gradients in our original data, the majority of the differences between stations are significant, so we only give the results of pairwise tests in which differences between groups were not significant (Table 2). It is immediately apparent that

Table 2. Summary of results from 1-way ANOSIM. Value of ANOSIM statistic $(R)$ for global test for differences between groups in each matrix ( $p<0.001$ in all cases), and results of pairwise tests in which $p>0.05$

\begin{tabular}{|c|c|c|c|c|c|c|c|c|c|c|}
\hline \multicolumn{3}{|c|}{ Nematodes } & \multicolumn{3}{|c|}{ Macrofauna } & \multicolumn{2}{|c|}{ Nematodes } & Fal estuary system & \multicolumn{2}{|l|}{ Macrofauna } \\
\hline Stns & $R$ & $\mathrm{p}$ & Stns & $R$ & $\mathrm{p}$ & Creek & $R$ & $\mathrm{p}$ & Creek $\quad R$ & p \\
\hline \multicolumn{3}{|c|}{ Species $($ global $R=0.716)$} & \multicolumn{3}{|c|}{ Species $($ global $R=0.678)$} & \multicolumn{3}{|c|}{ Species (global $R=0.816)$} & \multicolumn{2}{|l|}{ Species (global $R=0.492)$} \\
\hline 2,3 & 0.219 & 0.114 & 2,3 & 0.042 & 0.457 & & - & - & Mylor, Percuil -0.012 & 0.532 \\
\hline 4,5 & 0.094 & 0.229 & 3,6 & 0.271 & 0.171 & & & & & \\
\hline \multicolumn{3}{|c|}{ Genus (global $R=0.690)$} & \multicolumn{3}{|c|}{ Genus (global $R=0.647)$} & \multicolumn{3}{|c|}{ Genus (global $R=0.817$ ) } & \multicolumn{2}{|l|}{ Genus (global $R=0.493$ ) } \\
\hline 2,3 & 0.208 & 0.086 & 2,3 & -0.010 & 0.571 & & - & - & Mylor, Percuil -0.056 & 0.635 \\
\hline 4,5 & 0.052 & 0.257 & 3,6 & 0.271 & 0.114 & & & & & \\
\hline \multicolumn{3}{|c|}{ Family (global $R=0.494$ ) } & \multicolumn{3}{|c|}{ Family (global $R=0.665)$} & \multicolumn{3}{|c|}{ Family (global $R=0.725)$} & \multicolumn{2}{|l|}{ Family (global $R=0.479$ ) } \\
\hline 1,2 & 0.240 & 0.086 & 2,3 & 0.052 & 0.371 & Mylor, Percuil & 0.176 & 0.111 & Mylor, Percuil 0.052 & 0.333 \\
\hline 1,3 & 0.271 & 0.057 & 3,6 & 0.167 & 0.229 & & & & & \\
\hline 1,6 & 0.438 & 0.057 & 4,5 & 0.260 & 0.086 & & & & & \\
\hline 1,7 & 0.177 & 0.200 & & & & & & & & \\
\hline 2,6 & 0.406 & 0.057 & & & & & & & & \\
\hline 4,5 & 0.240 & 0.143 & & & & & & & & \\
\hline 5,6 & 0.417 & 0.086 & & & & & & & & \\
\hline \multicolumn{3}{|c|}{ Trophic groups (qlobal $R=0.305)$} & \multicolumn{3}{|c|}{ Phylum (global $R=0.668)$} & \multicolumn{3}{|c|}{ Trophic groups (global $R=0.513$ ) } & \multicolumn{2}{|l|}{ Phylum (global $R=0.422$ ) } \\
\hline 1,2 & -0.115 & 0.743 & 2,3 & -0.010 & 0.543 & Mylor, Pill & 0.044 & 0.254 & Mylor, St Just & 0.079 \\
\hline 1,3 & -0.063 & 0.600 & 3.7 & 0.135 & 0.229 & Mylor, St Just & 0.204 & 0.071 & Mylor, Percuil - 0.100 & 0.675 \\
\hline 1,7 & -0.146 & 0.686 & 5,6 & 0.469 & 0.057 & Mylor, Percuil & 0.356 & 0.056 & & \\
\hline 2,3 & -0.167 & 0.800 & & & & Pill, St Just & 0.116 & 0.103 & & \\
\hline 2,5 & 0.573 & 0.057 & & & & & & & & \\
\hline 2,6 & 0.354 & 0.086 & & & & & & & & \\
\hline 2,7 & -0.104 & 0.629 & & & & & & & & \\
\hline 3,6 & 0.292 & 0.114 & & & & & & & & \\
\hline 3,7 & -0.323 & 1.000 & & & & & & & & \\
\hline 4,5 & 0.385 & 0.114 & & & & & & & & \\
\hline 5,6 & 0.500 & 0.057 & & & & & & & & \\
\hline 5,7 & 0.552 & 0.057 & & & & & & & & \\
\hline 6,7 & 0.292 & 0.057 & & & & & & & & \\
\hline
\end{tabular}


aggregating nematode abundances above the level of genus alters the apparent pattern at both sites, and discrimination between groups of samples begins to break down, albeit only slightly in the Fal estuary, with differences between 2 creeks becoming marginally insignificant at the level of families. For macrofauna the pattern of intergroup discrimination begins to break down at the level of families in the sublittoral situation, but again only slightly, with differences between 2 extra stations being marginally insignificant at the level of families. In the estuarine mudflats pattern only begins to break down at the level of phyla. In both situations ANOSIM using matrices derived from phyletic abundances of macrofauna is better at discriminating between groups of samples than trophic groups of nematodes, but the patterns of significant differences are not the same as those in analyses of lower taxonomic levels.

\section{DISCUSSION}

No notable differences between analyses of species abundance data and analyses of genus abundances were apparent in this study. In sublittoral benthic communities consistent differences were found between patterns in analyses of nematode abundances at the levels of species or genera, and patterns in analyses of macrofauna abundances at the levels of species, genera or families. Aggregation of nematode or macrofaunal data to higher taxonomic levels produced a shift in apparent changes in community structure and reduced the ability of ANOSIM to discriminate between stations. This is not to say that data aggregated to higher taxonomic levels are not of use, however. Stn 4 . and to a lesser extent Stn 5, within the disposal site, are still seen to be different to the rest, indicating an impact as a result of dredgings disposal. In the Fal estuary all the creeks were significantly different in analyses of nematode data at the levels of species and genera, whereas at the level of families the discrimination between Mylor \& Percuil Creeks was lost. Analyses of trophic groups did not discriminate between most of the creeks, but again the most impacted creek, Restronguet (Somerfield et al. 1994a), was separated from the others. As expected, aggregation of macrofaunal abundance data from the intertidal mudiats to families had little effect, and to phyla had some effect, although the results are still interpretable

In conclusion, using new and more objective techniques, the findings of previous studies (e.g. Heip et al. 1988, Herman \& Heip 1988, Warwick 1988a, b, c, Gray et al. 1990, Warwick et al. 1990) that analyses of sublittoral nematode communities are robust to aggregation to the level of genus, but further aggregation begins to alter the perceived pattern of impact, are confirmed. In the present study these findings are extended to an intertidal estuarine nematode community. In so far as these samples are typical, we can also say that aggregation of macrofauna abundances to families has only a small effect on analyses of diverse sublittoral communities, and none on analyses of intertidal macrofauna. Aggregating macrofauna data to phyla has some effect on consequent analyses in both situations. Whichever component of the benthos is examined, and at whatever taxonomic level the analyses are carried out, interpretable results are possible, especially if the pattern of community change is marked, as it is at both the sites examined in this study. That being said, it must be remembered that the detection of a change in community structure at the level of phylum, in response to a putative pollution gradient, tells us little about the nature of that response, and that for examining issues of causality, or for designing laboratory experiments to investigate a pollution effect, some knowledge of the species present, and their ecology, may be required.

Acknowledgements. This work was funded by the UK Ministry of Agriculture, Fisheries and Food as part of an evaluation of the use of meiofauna in marine pollution monitoring programmes (project no. AE0210).

\section{LITERATURE CITED}

Bayne BL, Clarke KR, Gray JS (1988) Biological effects of pollutants: results of a practical workshop. Mar Ecol Prog Ser $46: 1-278$

Bray JR, Curtis JT (1957) An ordination of the upland forest communities of Southern Wisconsin. Ecol Monogr 27 : $325-349$

Clarke KR (1993) Non-parametric multivariate analyses of changes in community structure. Aust J Ecol 18:11.7-143

Clarke KR, Green RH (1988) Statistical design and analysis for a 'biological effects' study. Mar Ecol Prog Ser 46: $213-226$

Clarke KR, Warwick RM (1994a) Simlarity-based testing for community pattern: the 2 -way layout with no replication. Mar Biol 118:167-176

Clarke KR, Warwick RM (1994b) Changes in marine communities: an approach to statistical analysis and interpretation. Plymouth Marine Laboratory, Plymouth

Clarke KR, Warwick RM, Brown BE (1993) An index showing breakdown of seriation, related to disturbance, in a coralreef assemblage. Mar Ecol Prog Ser 102:153-160

Ferraro SP, Cole FA (1990) Taxonomic level and sample size sufficient for assessing pollution impacts on the Southern California Bight macrobenthos. Mar Ecol Prog Ser 67: $251-262$

Gray JS, Clarke KR, Warwick RM, Hobbs G (1990) Detection of initial effects of marine pollution on marine benthos: an example from the Ekofısk and Eldfisk oilfıelds, North Sea. Mar Ecol Prog Ser 66:285-299

Heip C, Warwick RM, Carr MR, Herman PMJ, Huys R, Smol N, Van Holsbeke K (1988) Analysis of community attrib- 
utes of the benthic meiofauna of Frierfjord/Langesundfjord. Mar Ecol Prog Ser 46:171-180

Herman PMJ, Heip C (1988) On the use of meiofauna in ecological monitoring: who needs taxonomy? Mar Poliut Bull 19:45-60

Kruskal JB, Wish M (1978) Multidimensional scaling. Sage Publications, Beverly Hills

Somerfield PJ, Gee JM, Warwick RM (1994a) Soft sediment meiofaunal community structure in relation to a long-term heavy metal gradient in the Fal estuary system. Mar Ecol Prog Ser 105:79-88

Somerfield PJ, Gee JM, Warwick RM (1994b) Benthic community structure in relation to an instantaneous discharge of waste water from a tin mine. Mar Pollut Bull 28:363-369

Somerfield PJ, Rees HL, Warwick RM (1995) Interrelationships in community structure between shallow water marine meiofauna and macrofauna in relation to dredgings disposal. Mar Ecol Prog Ser (in press)

Warwick RM (1988a) Analysis of community attributes of

This article was submitted to the editor the macrobenthos of Frierfjord/Langesundfjord at taxonomic levels higher than species. Mar Ecol Prog Ser 46: $167-170$

Warwick RM (1988b) Effects on community structure of a pollutant gradient - summary. Mar Ecol Prog Ser 46: $207-211$

Warwick RM (1988c) The level of taxonomic discrimination required to detect pollution effects on marine benthic communities. Mar Pollut Bull 19:259-268

Warwick RM (1993) Environmental impact studies on marine communities: pragmatical considerations. Aust J Ecol 18: $63-80$

Warwick RM, Platt HM, Clarke KR, Agard J, Gobin J (1990) Analysis of macrobenthic and mejobenthic community structure in relation to pollution and disturbance in Hamilton Harbour, Bermuda. J exp mar Biol Ecol 138:119-142

Wieser W (1953) Die Beziehung zwischen Mundhöhlengestalt, Ernährungsweise und Vorkommen bei freilebenden marinen Nematoden. Ark Zool 4:439-484

Manuscript first received: March 9, 1995

Revised version accepted: June 6, 1995 